Reseñas

\section{Marijn Molema and Sara Svensson. Regional Economic Development and History. London, Routledge, 2019, 208 pp. ISBN: 9781138334137.}

How industrialization spread across European regions? This could be the main example of the kind of questions to be answer in Regional Economic Development and History. The main statement or definition of this book is the critical role of history to understand regional patterns. The chapters presented in this collection are part of new and interesting line of research lead by economic historians, such as the new books by (Tirado-Fabregat and Badia-Miró, 2020; Rosés and Wolf, 2018) geographical, economic, institutional, and political factors have all worked together. Lessons from the past can aid current debates on regional inequalities, territorial cohesion, and public policies in developing and also developed countries. In contrast with European countries, Latin American economies largely specialized in commodity exports, showed high levels of urbanization and high transports costs (both domestic and international). The book is divided in three parts, each of one with two or three chapters.

The first part, "Disciplinary and theoretical explorations", contents two chapters one written by Molema and Tomaney, where they defend the relevance to use historical knowledge to understand regional development patterns. The present and future seem to be attached to the institutional research, a kind of topic that needs the collaboration from history. The authors done a wise self-critic to historians and their absence on regional analysis and debates. The last chapter of this section, written by Huggins and Thompson, describe the links between behavioural economic geography and regional history. The goal of the chapter ("a behavioural theory of how such cities and regions evolve and develop") appears to be ambitious for a short book section. Moreover, the lovely maps of page 45 are difficult to read because of the black-grey scale.

The second part of the book, entitled "Innovations in research design and methodology" presents three studies. The first one, "An interdisciplinary approach to the persistent effects of polish partitions on educational achievements" establish the path dependence between historical events and present-day educational achievements in Poland. The chosen country could be the ideal one to analyse the regional changes through history. The interdisciplinary approach (econometrics, cartography, and sociology) gave to the article an interesting output that can be use in further research. In the chapter "Regional GDP before GDP", Enflo and Missiaia done a comprehensive survey on national accounts methods to estimate regional historical inequality. They started from the perspective that present studies of inequality could be enhanced with a historical perspective. The Swedish case, presented as example in this chapter, has shed light in the different approaches to calculate historical regional GDP. The final chapter of this section, entitled "Comparative research designs", written by M. Åberg and T. Denk, analyses the challenges and opportunities of regional studies in historical and social sciences perspectives. They conclude that Comparative Sequence Design (CSD) offers the best solution to face the challenges of regional historical studies, given the capacity of the method to be use in diachronic and synchronic comparisons.

The final part of the book, "Empirical case studies", three regional cases in different times-span. The first one, written by T. Fernández de Sevilla and A. Dalla Costa, is about the Brazilian automotive industry cluster in Sao Paulo (1900-1970). This interesting topic is analysed in a traditional business history approach, linking the automotive industry with the developmental policy implemented by Brazilian authorities. The regional aspect of this study is the relation with the cluster theory of Alfred Marshall, because the industrial policy is not enough to explain the success of this sector. "Urban and regional development policy", written by K. Cox, explains the differences between USA and Western Europe on urban planning and how the role of the State (or its absence) has shaped urban planning post Second World War. The last chapter of the book, "Spatial-economic development", by M. Wang and B. van Leeuwen, is about the relation between urbanization and human capital in the China post Den Xiaoping reforms (19802018). The chapter have some conclusions that could be debatable, such as define the Reform period as a reestablishment of the pre-1949 situation. A valuable output of this book section is the mention of all the social externalities of Chinese regional inequality (rural vs urban areas).

The book itself is a good compilation of research agenda, methodologies, and case studies, but it lacks a clear line (a handicap quite common in these edited volumes). E.g., the first five chapters are using examples mainly from Europe. However, the three case studies are from Latin America, USA (and a bit about Western Europe) and Asia. The case studies are extremely relevant, and I do not have any particular critics to these works, but the flow of the book was altered (or confused) when the examples chosen to prove or to reinforce the main research questions of the edited collection are not in the same regional area. The methodological and theoretical foundations of the book would be reinforced if the case studies were related specifically to the methods and theories presented in the first two parts. Surprisingly, an edited collection on regional studies and history contents only 6 figures (Figure 9.1, It is a graph that could be a table). A reader would expect more maps and GIS support in a book on these topics.

In general, the collection has done an interesting approach to the challenges and the opportunities of the interdisciplinary 
research between history and regional studies. The conclusion written by M. Molema summarized in excellent way the findings and the further research that this book has proposed.

\section{Bibliography}

Rosés, J. R. and Wolf, N. (2018). The Economic Development of Europe's Regions: A Quantitative History since 1900. Routledge. Available at: https://doi.org/10.4324/9780429449789.
Tirado-Fabregat, D. A. and Badia-Miró, M. (eds.) (2020). Time and Space Latin American Regional Developments Historical Perspective. Palgrave MacMillan.

Cristián Ducoing Lund University 